\title{
Neuroimmune system-mediated renal protection mechanisms
}

\author{
Tsuyoshi Inoue $^{1}$ D
}

Received: 20 January 2021 / Accepted: 9 April 2021 / Published online: 20 April 2021

(c) The Author(s) 2021

\begin{abstract}
The autonomic nervous system plays an important role in maintaining homeostasis in organisms. Recent studies have shown that it also controls inflammation by directly altering the function of the immune system. The cholinergic anti-inflammatory pathway (CAP) is one of the neural circuits operating through the vagus nerve. Acetylcholine released from the terminal of the vagus nerve, which is a parasympathetic nerve, acts on the $\alpha 7$ nicotinic acetylcholine receptor of macrophages and reduces inflammation in the body. Previous animal studies demonstrated that vagus nerve stimulation reduced renal ischemiareperfusion injury. Furthermore, restraint stress and pulsed ultrasound had similar protective effects against kidney injury, which were mainly thought to be mediated by the CAP. Using optogenetics, which can stimulate specific nerves, it was also revealed that activation of the CAP by restraint stress was mediated by $\mathrm{C} 1$ neurons in the medulla oblongata. Nevertheless, there still remain many unclear points regarding the role of the nervous and immune systems in controlling renal diseases, and further research is needed.
\end{abstract}

Keywords Vagus nerve stimulation · Acetylcholine receptor · Cholinergic anti-inflammatory pathway · Optogenetics . Acute kidney injury $\cdot$ Nervous system

\section{Introduction}

It has long been suggested that the immune system depends on the state of mind, as validated by the phrase "disease is from the mind." So far, it has been revealed that immune cells, such as macrophages, dendritic cells, T cells, and B cells, express receptors for neurotransmitters on their surface and directly receive signals from the nervous system to change their dynamics [1]. Recently, it was reported that inflammatory diseases, including kidney disease, involve such control of the immune system by the autonomic nervous system [2,3]. This observation has progressed to therapeutic applications in some diseases. This paper outlines the relationship between the nervous system and the immune system, with a focus on kidney disease.

This article was presented as the Oshima Award memorial lecture at the 63th annual meeting of the Japanese Society of Nephrology, held at Yokohama, Japan, in 2020.

Tsuyoshi Inoue

ts-inoue@nagasaki-u.ac.jp

1 Department of Physiology of Visceral Function and Body Fluid, Nagasaki University Graduate School of Biomedical Sciences, 1-12-4, Sakamoto, Nagasaki 852-8523, Japan

\section{Neuron-immune interactions and the cholinergic anti-inflammatory pathway (CAP)}

The hypothalamic-pituitary-adrenal axis is a glucocorticoid-mediated innate immune response mechanism that is controlled by the central nervous system, specifically the paraventricular nucleus of the hypothalamus [4]. It was discovered in the 1920s that the nervous system regulates inflammatory responses via hormones. Subsequently, attention was focused on neural circuits mediated by inflammatory cytokines, such as tumor necrosis factor (TNF)- $\alpha$ and interleukin-1, and receptors, and it was found that the vagus nerve was involved in this reaction [5, 6]. Cytokines produced by damaged cells activate afferent sensory nerves and bind to the receptors on afferent vagus nerves to signal solitary nuclei of the brain stem and regulate the immune response of peripheral tissues. However, because these anti-inflammatory effects are also linked to the hypothalamic-pituitary-adrenal axis, it was unclear how the vagal afferents were activated.

A breakthrough in the hypothesized interaction between the nervous and immune systems was the proposal of the inflammatory reflex by Tracey's group [7]. In 2000, it was 
discovered in a rat sepsis model created by lipopolysaccharide administration that direct electrical stimulation of the vagal efferent tract suppressed the production of TNF- $\alpha$ (an inflammatory cytokine) and, consequently, shock. This effect was obviated by vagotomy, indicating that it involved a series of reflex reactions by neural circuits [8]. At the same time, it was identified that the reaction was stimulated by acetylcholine (ACh) through its receptors on macrophages. They named this series of vagus nerve-mediated responses as the CAP. Later, using $\alpha 7$ nicotinic acetylcholine receptor $(\alpha 7 \mathrm{nAChR})$-knockout mice, it was clarified that the $\alpha 7$ subunit of the nicotinic receptor was important among ACh receptors [9]. In experiments using a sepsis mouse model, it was found that the spleen contributed to the production of TNF- $\alpha$, and splenectomy diminished the effect of vagus nerve stimulation (VNS). This revealed the importance of the spleen in the CAP [10].

$\mathrm{ACh}$ is released from vagus nerve endings, whereas the splenic nerve is adrenergic, suggesting the involvement of other intervening factors between the vagus and splenic nerves. Although there are still unclear points about its comprehensive processes, the current understanding of the CAP in kidney injury is based on the findings detailed and illustrated in Fig. 1. Local inflammation is sensed by the afferent vagus nerve and transmitted to the central nervous

\section{VNS, C1 neuron stimulation, restrain stress and pulsed ultrasound}

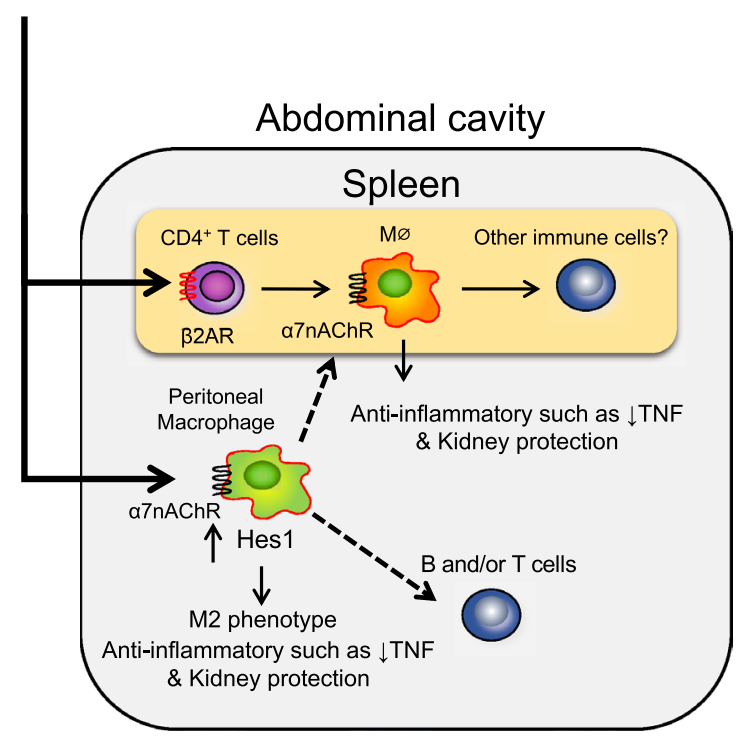

Fig. 1 Current understanding of the cholinergic anti-inflammatory pathway in kidney injury. Based on reports centered on sepsis and our data on the kidney, the cholinergic anti-inflammatory pathway in kidney diseases, as understood to date, is shown. It is assumed that various immune cells work cooperatively in the pathway to protect the kidney. $\beta 2 \mathrm{AR}, \beta 2$ adrenergic receptor, $\alpha 7 \mathrm{nAChR}, \alpha 7$ nicotinic acetylcholine receptor system. After that, it is transmitted to the spleen via the efferent vagus and splenic nerves, and noradrenaline is released from the splenic nerve endings. Noradrenaline binds to $\beta 2$ adrenergic receptors present on specific $\mathrm{T}$ cells $\left(\mathrm{CD} 4+\mathrm{CD} 44^{\text {high }} \mathrm{CD} 62 \mathrm{~L}^{\text {low }}\right.$ memory T cells) that have choline acetyltransferase (ChAT), an ACh synthase, and releases $\mathrm{ACh}$ [11]. It is believed that the ACh released from CD4 + T cells binds to $\alpha 7 \mathrm{nAChR}$ on macrophages and attenuates the release of inflammatory cytokines, such as TNF- $\alpha$, from macrophages, thus suppressing inflammation. However, it is still unknown how the parasympathetic vagus nerve activates the sympathetic splenic nerve. As mentioned earlier, the CAP may involve more complex mechanisms.

\section{VNS and acute kidney injury (AKI)}

AKI is a rapid deterioration of renal function caused by various factors such as ischemia, sepsis, and drugs. Both innate and adaptive immunity are involved in the pathology of AKI, and various immune cells are intricately intertwined in space and time to cause inflammation [12]. It is not known how the neuroimmune linkage affects this condition. Therefore, we first investigated how VNS affected the pathophysiology of AKI [13]. The most commonly used model of AKI is bilateral ischemia-reperfusion injury (IRI), which clinically corresponds to renal injury after cardiac surgery or transplantation. Our method of stimulation of the vagus nerve with electricity is shown in Fig. 2. When VNS was performed on wild-type mice $24 \mathrm{~h}$ before bilateral IRI, renal function and renal pathological findings were significantly improved (Fig. 3a), and systemic TNF- $\alpha$ level was also decreased [13]. However, this anti-inflammatory effect was not observed in splenectomized or $\alpha 7 \mathrm{nAChR}$-knockout mice, suggesting that both the spleen and $\alpha 7 \mathrm{nAChR}$ are involved in VNS-induced kidney protection (Fig. 3b) [13]. Furthermore, when bilateral IRI was induced after splenocytes were adoptively transferred from wild-type mice that received VNS, renal damage of the recipient was significantly reduced. In contrast, similar experiments conducted with $\alpha 7 \mathrm{nAChR}$-knockout mice as splenocyte donors showed no effect, demonstrating that the anti-inflammatory effect of VNS on IRI is mediated by $\alpha 7$ nAChR-positive splenocytes (Fig. 3c) [13].

What exactly does VNS change in splenocytes? Results of previous experiments showed that the phenotypes of macrophages migrating into the kidney after injury were changed by VNS [13]. The levels of arginase 1, a well-known marker of anti-inflammatory macrophages (M2), were increased significantly in the kidneys of wild-type mice that underwent IRI after VNS. Increased expression of arginase 1 was not observed in $\alpha 7 \mathrm{nAChR}$-knockout mice treated with VNS. It is believed that such macrophage phenotypic changes can 
Fig. 2 Vagus nerve stimulation. The method of vagus nerve stimulation by electricity is shown. After identifying the vagus nerve in the left neck, two electrodes were applied to the nerve to perform electrical stimulation
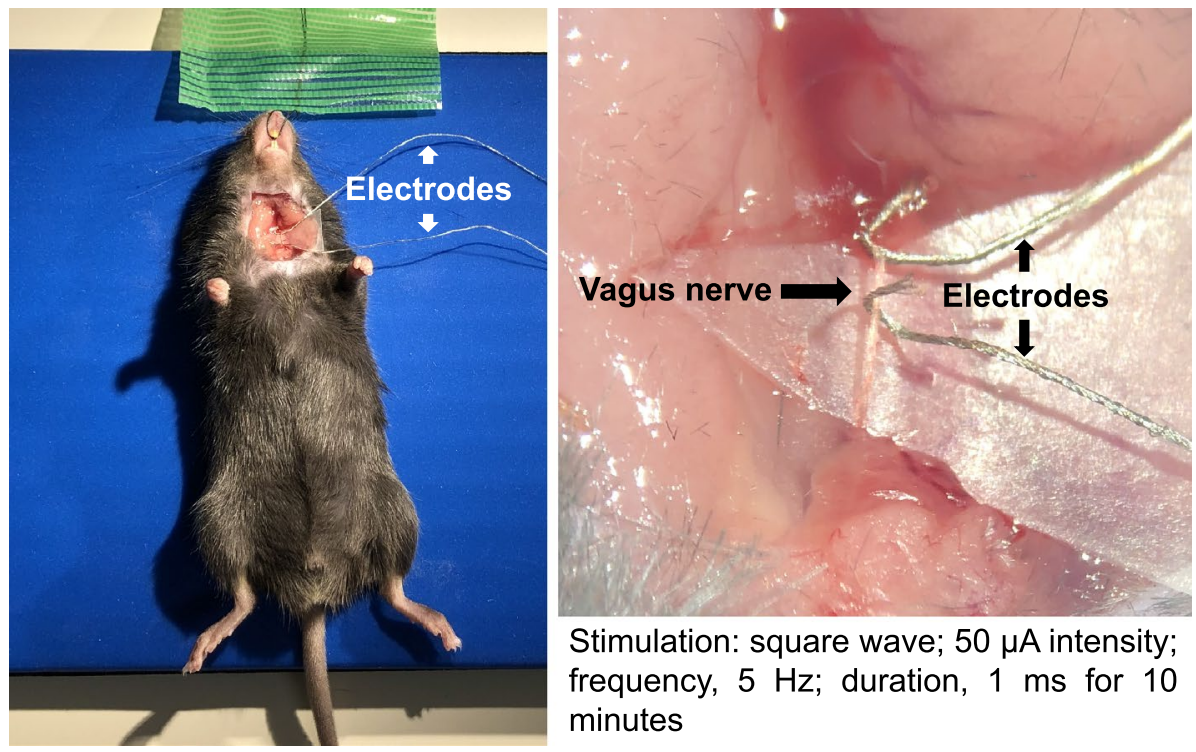

Stimulation: square wave; $50 \mu \mathrm{A}$ intensity; frequency, $5 \mathrm{~Hz}$; duration, $1 \mathrm{~ms}$ for 10 minutes explain at least part of the anti-inflammatory and organprotective effects in the kidney elicited by VNS.

From these results, we focused on $\alpha 7 \mathrm{nAChR}$-positive macrophages and explored their role in the CAP [14]. When peritoneal macrophages from wild-type mice were pretreated with nicotine (an agonist of nicotinic receptors including $\alpha 7 \mathrm{nAChR}$ ) and transplanted into another mouse, they acted protectively against the recipient's kidney IRI. This effect was not observed in experiments using $\alpha 7 \mathrm{nAChR}$-knockout mice as donors, suggesting that $\alpha 7 \mathrm{nAChR}$ on macrophages is important (Fig. 3d). Therefore, among the genes whose expression increased significantly when peritoneal macrophages collected from wild-type mice were treated with nicotine, the genes whose expression did not increase when

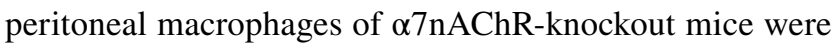
treated with nicotine were analyzed using RNA-seq. Upon screening, one of the basic helix-loop-helices, hairy and enhancer of split-1 (Hes1), was extracted as a candidate downstream gene. VNS induced Hes1 expression in peritoneal macrophages, and knocking down Hes 1 in peritoneal macrophages suppressed the anti-inflammatory effect observed with nicotine administration. In addition, overexpression of Hes1 showed an anti-inflammatory effect, and the macrophage phenotype changed toward M2. Furthermore, adoptive transfer of Hes1-overexpressing macrophages into mice reduced renal IRI. These results suggest that VNS increased the expression of Hes1 through $\alpha 7 \mathrm{nAChR}$ of macrophages and exerted a renal protective effect by changing the macrophage phenotype toward M2 (Fig. 3e).

In the above studies, we performed VNS before inducing kidney damage, and thus concluded that it had a renal protective effect. However, most clinical settings present patients with pre-existing kidney injury; therefore, we focused on the renal protective effect of VNS after the kidney was damaged. Cisplatin is a widely used anticancer agent. Approximately one-third of the patients who receive cisplatin suffer from AKI. Therefore, we evaluated the effect of VNS using an animal model of cisplatin-induced nephropathy. The results confirmed that VNS had an organ-protective effect, even post-cisplatin-induced nephropathy, and that CCL2 and CCL11, factors related to immune cell chemotaxis, were suppressed in macrophages through $\alpha 7 n A C h R$ (Fig. 3f) [15].

\section{C1 neuron stimulation activates the CAP and protects the kidney}

With the advent of optogenetics, it is now possible to manipulate the activity of specific neurons with light [11] and grasp the roles of nerves more accurately. $\mathrm{C} 1$ neurons in the medulla oblongata project into the intermediolateral cell column and the dorsal motor nucleus of the vagus and control the sympathetic and vagus nerves. $\mathrm{C} 1$ neurons are activated by inflammatory cytokines and lipopolysaccharide, and it has been thought that they are deeply involved in the inflammatory process; however, the details remain unknown. Therefore, we attempted to elucidate the role of $\mathrm{C} 1$ neurons using an AKI model (bilateral IRI). When short-term restraint stress (restraining mice in a closed position thereby activating autonomic nerves) was applied, renal damage after bilateral IRI was markedly suppressed. This anti-inflammatory effect after restraint stress was not observed in $\alpha 7$ nAChR-knockout mice. Furthermore, when spleen cells collected from a mouse subjected to restraint stress were transplanted into another mouse and IRI was then performed on the recipient, renal damage was also alleviated. In other words, $\alpha 7 \mathrm{nAChR}$ and spleen cells were both 
A
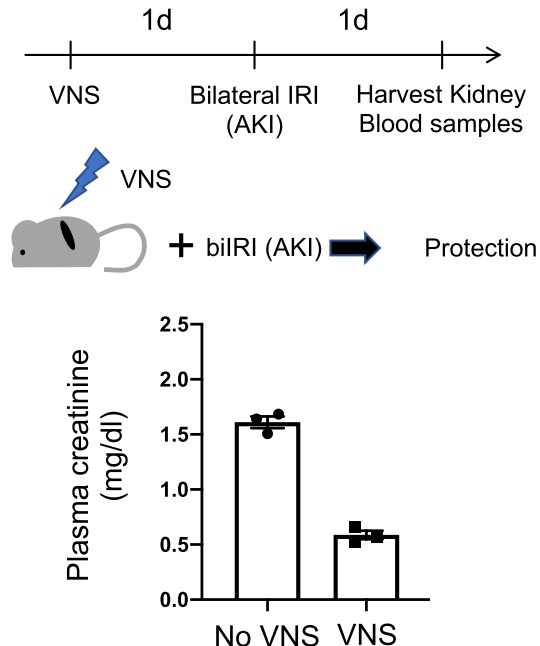

B

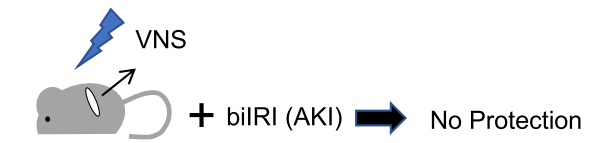

No spleen

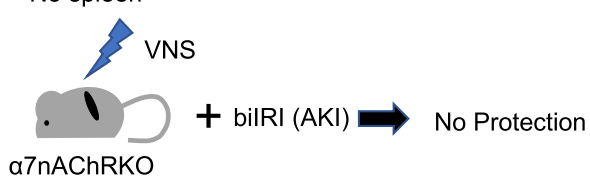

E

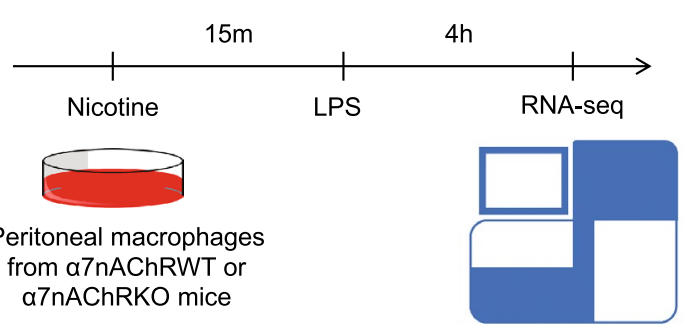

$\underline{\text { RNA-seq identified Hes1 as a downstream gene of } \alpha 7 n A C h R}$

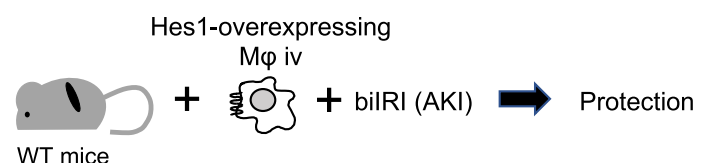

Fig. 3 Summary of the role of vagus nerve stimulation (VNS) on acute kidney injury. a Prior VNS protects the kidney from ischemiareperfusion injury. b The kidney protective effect by VNS is lost in splenectomized or $\alpha 7 n$ AChR-deficient mice. c Adoptive transfer of splenocytes from mice who have $\alpha 7 \mathrm{nAChR}$ and received VNS protects the kidney. d Adoptive transfer of nicotine-treated macrophages isolated from wild-type (WT) mice protect the kidney. The protec-

important, suggesting that the CAP is also involved in the renal protective effect of restraint stress.

We tested the hypothesis that $\mathrm{C} 1$ neurons were involved in the activation of the CAP. Channelrhodopsin-2 (a photoactivated non-selective cation channel found in green algae) [16]
C
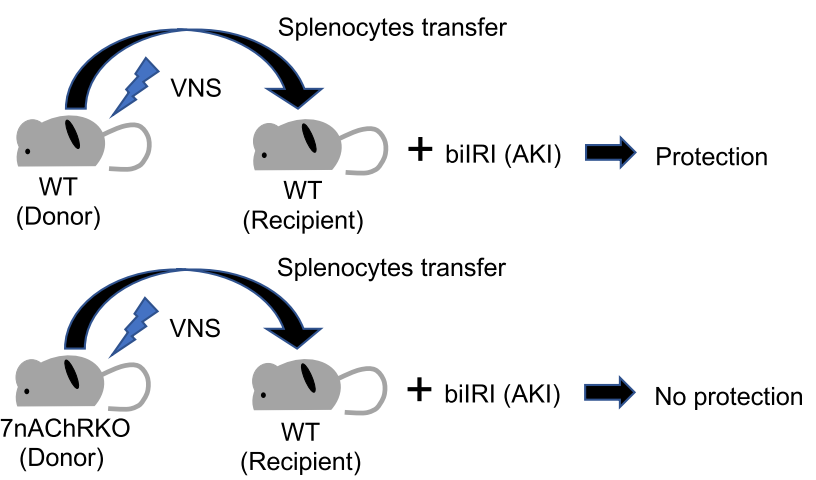

D
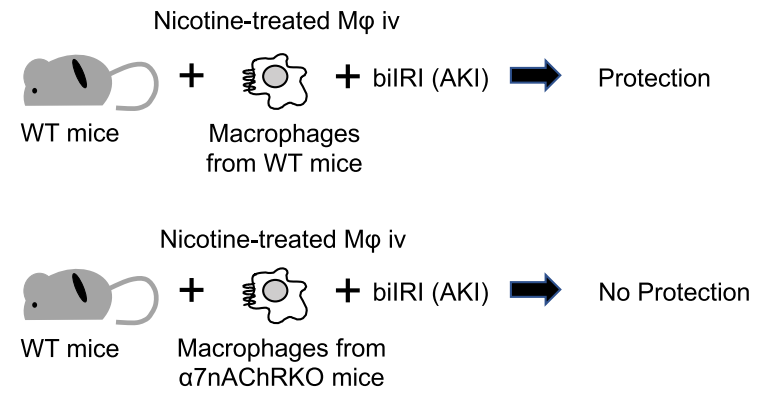

$\mathrm{F}$
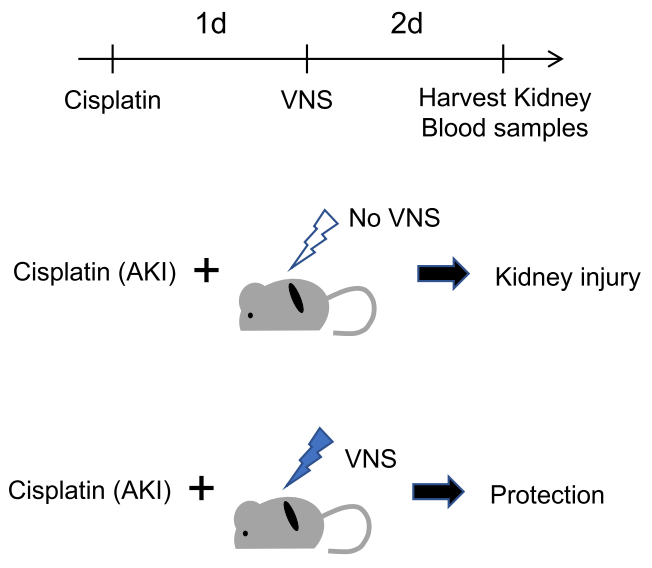

tive effect is lost when nicotine-treated macrophages isolated from $\alpha 7 \mathrm{nAChR}$-deficient mice are adoptively transferred. e RNA-seq identified Hes 1 as a downstream gene of $\alpha 7 \mathrm{nAChR}$ in macrophages. Nicotine was used as an agonist for acetylcholine receptors and lipopolysaccharide was used to induce inflammation in macrophages. $\mathbf{f}$ VNS has an organ-protecting effect even after the induction of kidney damage by cisplatin

was used with optogenetics to selectively stimulate $\mathrm{C} 1$ neurons. This stimulation reduced renal damage after bilateral IRI as well as restraint stress (Fig. 4) [17]. When restraint stress was applied after selectively inhibiting $\mathrm{C} 1$ neurons, this renal protective effect disappeared, demonstrating that 

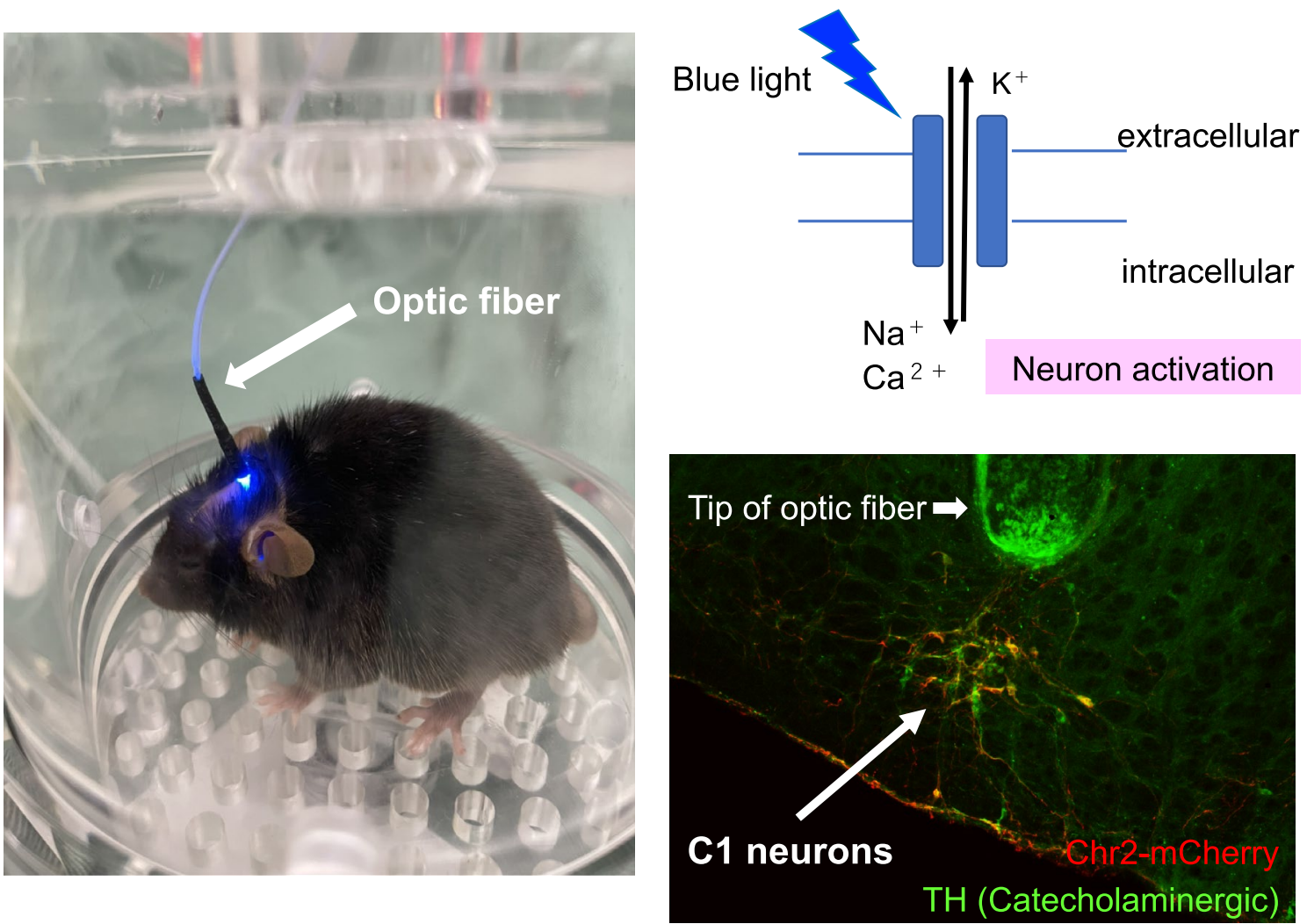

Fig. 4 C1 neuron stimulation with optogenetics. Channelrhodopsin-2 (ChR2) is a photoactivated non-selective cation channel, and neurons expressing ChR2 can be activated by blue light. Five to six weeks after virus injection with $\mathrm{ChR} 2$ into $\mathrm{C} 1$ regions and implantation of the optic fiber, $\mathrm{C} 1$ neurons express $\mathrm{ChR} 2$ and can be stimulated by

the renal protective effect of restraint stress was mediated by $\mathrm{C} 1$ neurons. However, the renal protective effect of $\mathrm{C} 1$ neuron stimulation was not diminished by blockade of the parasympathetic nervous system by subdiaphragmatic vagotomy and administration of an inhibitor of the corticosterone receptor, indicating that $\mathrm{C} 1$ neuron stimulation-induced kidney protection was mediated by the sympathetic nervous system. This suggests that the $\mathrm{C} 1$ neuron-related kidney protection mechanism is different from VNS, which is considered to be the parasympathetic nervous system, although the general framework of the CAP is common for both.

\section{Pulsed ultrasound activates the CAP}

We have also shown the preventive effect of pulsed ultrasound stimulation on AKI [14, 18, 19]. An ultrasound device (Sequoia 512) that is used in actual clinical practice (15L8w probe, Acuson, Indianapolis, IN, USA) was used for this study. Pulsed ultrasound stimulation was performed

a blue laser. ChR2 expression was confirmed in the $\mathrm{C} 1$ neurons (catecholaminergic) in the medulla oblongata. A small lesion surrounded by green autofluorescence shows the location of the tip of the optical fiber

under the contrast imaging mode for $2 \min$ at $7 \mathrm{MHz}$, and a mechanical index of 1.2. Renal damage was prevented by this ultrasound stimulation of the abdomen $24 \mathrm{~h}$ before bilateral renal IRI (the effect weakened with time but continued until 5 days) (Fig. 5). In addition, this effect was lost when the spleen was removed in advance, suggesting that the spleen is important for the renal protective effect of ultrasound. When Rag1-knockout mice lacking $\mathrm{T}$ and $\mathrm{B}$ cells received pulsed ultrasound stimulation and renal IRI, the protective effect was lost. Introducing wild type CD4-positive $\mathrm{T}$ cells into Rag1-knockout mice restored the protective effect, suggesting that CD4-positive cells are involved in the renal protection mechanism by ultrasound stimulation. In addition, this protective effect disappeared when splenectomy was performed before the transfer of CD4-positive cells [18]. Furthermore, blocking splenic sympathetic nerves with 6-hydroxydopamine, a neurotoxin that selectively destroys catecholamine-producing nerve endings, exacerbated renal IRI [19]. Collectively, these results suggest that the spleen, splenic sympathetic nerves, and CD4-positive T 

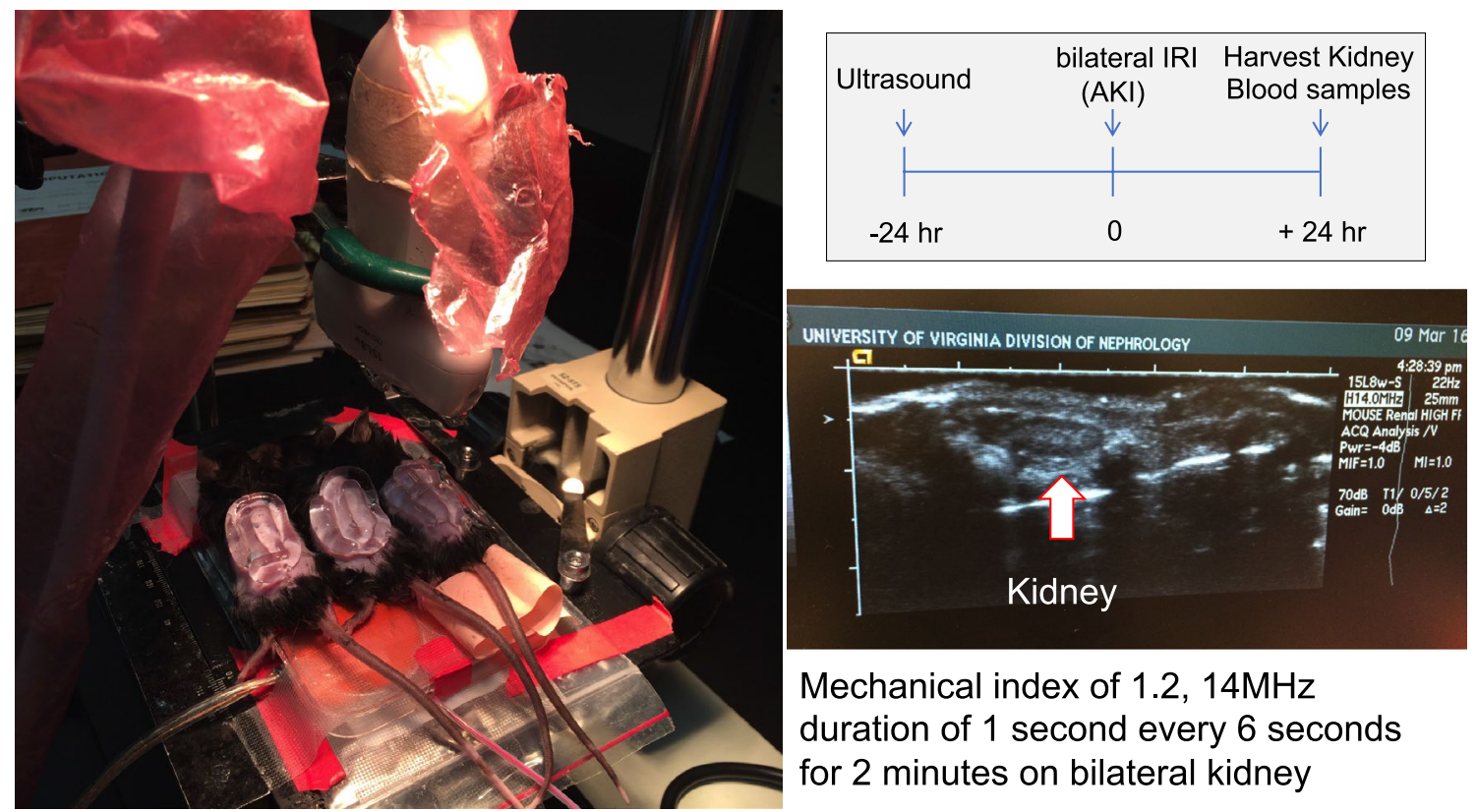

Mechanical index of $1.2,14 \mathrm{MHz}$

duration of 1 second every 6 seconds

for 2 minutes on bilateral kidney

Fig. 5 Pulsed ultrasound treatment for the prevention of acute kidney injury. This figure shows how we treated mice with pulsed ultrasound (left). The fur was shaved and then removed completely using a depilatory. Mice were then placed on a modified microscope stage that was positioned under an ultrasound transducer held in place with a ring clamp. A pre-warmed ultrasound gel was then placed on the depilated

cells are all involved in the renal protective effect of pulsed ultrasound. Furthermore, the use of $\alpha 7 \mathrm{nAChR}$ inhibitors eliminated the protective effect of ultrasound [18].

Levels of cytokines, such as TNF- $\alpha$, were decreased in plasma and kidneys of mice in which the renal protective effect was induced by prior ultrasound stimulation. The renal protective effect of ultrasound has been confirmed in a cecal ligation and puncture sepsis model [19] and in a renal IRI experiment using pigs (unpublished data). From the above results, it was considered that the preventive effect of ultrasound on AKI was mediated by the CAP as well as VNS, restraint stress, and $\mathrm{C} 1$ stimulation. Recently, Aibara et al. also showed that pulsed ultrasound ameliorated inflammation and renal fibrosis in hypertensive and diabetic nephropathy [20]. Thus, pulsed ultrasound treatment is a non-invasive therapeutic tool with no side effects, and this modality could be very useful for protecting the kidney. However, as shown in Fig. 5, the ultrasound probe used in our studies is considerably larger than the body of a mouse, and it is still unknown how and which organ the ultrasonic waves actually stimulate. There are some reports of how ultrasonic waves stimulate or inhibit nerves and cells. Thermal effects [21, $22]$ and mechanical effects $[23,24]$ are suggested as the mechanisms of nerve stimulation or inhibition by ultrasonic waves using ex vivo or in vitro studies. Recently, one paper demonstrated that focused ultrasound can elicit peripheral skin for ultrasound application. Mouse body temperature was monitored using a rectal probe (Fine Science Tools, Foster City, CA, USA) and maintained at $36 \pm 0.5{ }^{\circ} \mathrm{C}$ with a heating pad and heat lamp. The white arrow shows the kidney. The actual pulsed ultrasound stimulation was performed targeting the range shown in the photograph (right)

nerve stimulation with a physiological response in vivo [25]. Thus, it is possible that abdominal ultrasonography stimulates afferent nerves and ganglia in the abdominal cavity, and it is necessary to elucidate the detailed CAP activation mechanism in the future.

\section{Kidney nervous system}

In addition to the nervous system- and immune systemmediated kidney protection, I believe that the direct regulation of kidney cells by neurons also plays an important role in kidney protection. Therefore, I have summarized the kidney nervous system in Fig. 6. The relationship between the kidney and the nervous system was first reported in an animal renal denervation model in the mid-nineteenth century [26]. In the 1960s, attention was focused on the regulation of renal renin secretion by the nervous system [27]. Although renal innervation was unknown at that time, direct synaptic connections between nerve fibers inside the kidney and tubule epithelial cells were discovered between 1972 and 1973 [28]. Since then, interest in the regulation of renal function by the nervous system has increased. Further studies revealed that external innervation to the kidney included nerve fibers from the peritoneal plexus, superior mesenteric plexus, and the lumbar visceral plexus [29]. 


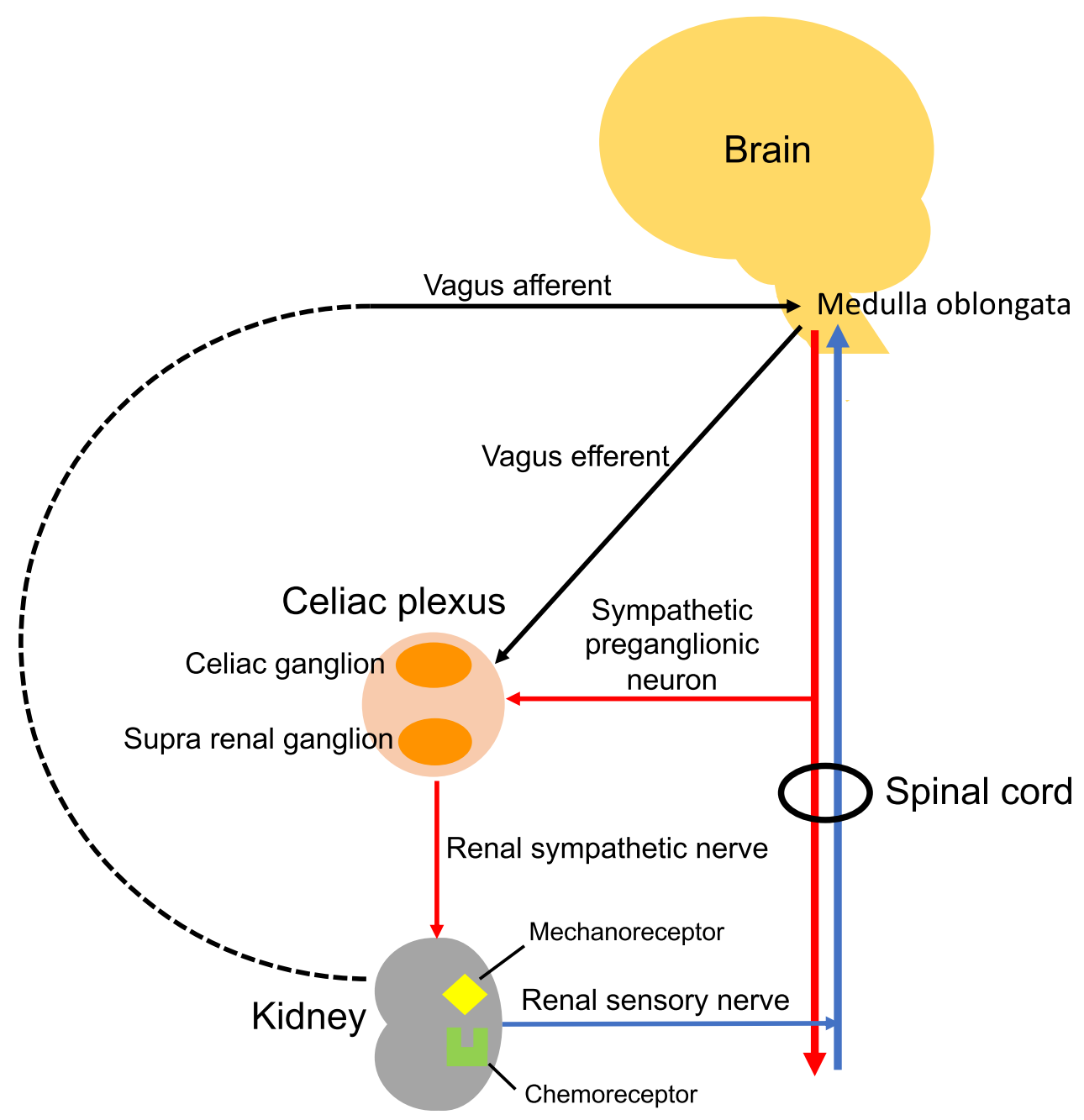

Fig. 6 Kidney nervous system. The kidney is mainly innervated by efferent sympathetic nerve fibers that accompany the blood vessels. Sympathetic preganglionic neurons reside in the intermediolateral cell column of the spinal cord synapse with the renal sympathetic nerve in the celiac plexus. Sensory afferent nerves having their cell body in the dorsal root ganglia synapse with neurons in the dorsal horn of the spinal cord transduce information to the medulla oblongata in the brain. Most of the vagal efferent branches begin in the dorsal motor nucleus of the medulla oblongata and branch to

The kidney is the intraperitoneal organ that receives the highest innervation next to the adrenal gland and is innervated by efferent sympathetic nerve fibers that accompany the blood vessels [30, 31]. The renal plexus consists of nerve fibers from the peritoneal ganglion, upper and lower renal ganglia, superior mesenteric ganglion, and thoracic visceral nerve; the renal plexus mainly comprises adrenergic neurons with noradrenaline as the primary neurotransmitter [31]. Although adrenergic neurons mainly control vascular smooth muscle cells, the presence of nerve endings has been confirmed in sites other than blood vessels, suggesting direct control of renal tubules by sympathetic nerves. In animals, the presence of neural junctions [32], and direct organs through intramural ganglia including ganglia located in the celiac plexus. The vagal afferent fibers reach mainly the solitary tract nucleus in the medulla oblongata, but it is not clear whether the afferent fibers from the kidney reach it directly. There seems to be no direct vagus innervation of the kidney. Red lines indicate sympathetic efferent fibers and blue lines show sympathetic afferent (sensory) fibers. Black lines show vagus nerve and dotted line indicates nerve fibers that have not been proven to exist. Orange oval indicates ganglion

sympathetic nerve function regulation, have been observed in renal tubule cells [33]. However, no direct neural innervation of renal tubule cells has been observed in humans.

The afferent sensory nerves of the kidney are mainly located around the renal pelvis [34, 35]. Since they contain neural peptides, such as substance $\mathrm{P}$ and calcitonin gene-related peptide, the sensory nerves of the kidney also play roles as mechanical and chemical receptors [36] These nerves are activated by an increase in the internal pressure of the renal pelvis and changes in urinary composition [35]. The cell bodies of these sensory nerves are located in the dorsal root ganglion and synapse, with interneurons in the 
posterior horn of the spinal cord to transmit information to the central nervous system.

In contrast to the abundant sympathetic innervation, the presence of parasympathetic nerves in the kidney is unclear. The presence of nitric oxide synthase, a parasympathetic marker, was confirmed around the human renal artery [37]. ChAT was found in renal tubules of rats by immunostaining with an antibody. Although it has been reported that ChAT is expressed in the collecting duct [38], innervation of the parasympathetic nerve and its significance in the human kidney remain unknown.

\section{Conclusion, remarks, and future perspectives}

Autonomic nerves directly control the immune system and play an important role in kidney disease. Our findings demonstrate that renal damage can be alleviated by directly manipulating activities of the autonomic nervous system such as by VNS, restraint stress, $\mathrm{C} 1$ neuron stimulation with optogenetics, and pulsed ultrasound. However, the renal protection mechanism through nerves has not been fully established, and further studies are required to elucidate these mechanisms. Recently, a method for single-cell RNA-seq using the kidney was developed [39] and various studies utilizing single-cell RNA-seq analysis have been reported in the field of kidney research [40-44]. Indeed, we also elucidated the renal protection mechanism mediated by sympathetic nerve stimulation by utilizing single-cell RNA-seq of the kidney very recently [45]. In addition, in vivo biosensors for neurotransmitters, such as ACh [46] and norepinephrine [47], have been developed recently. Using these biosensors, it is possible to evaluate the activity of autonomic nerves in real time, which would further improve our understanding of the renal protection mechanism through nerves. Our laboratory aims to pave the way for the treatment of kidney disease using these cutting-edge methods.

Acknowledgements I thank the Japanese Society of Nephrology for this award. I also thank all past and present mentors, collaborators, colleagues, and trainees as well as the current members of my laboratory at Nagasaki University. I especially thank the great mentorships of Drs. Masaomi Nangaku, Reiko Inagi, Tatsuhiko Kodama, and Youichiro Wada at the University of Tokyo, and Mark D. Okusa and Patrice G. Guyenet at the University of Virginia. In addition, I thank Dr. Chikara Abe at Gifu University for being a very helpful collaborator. The author's work and career development were supported by Grant-in-Aid for Japan Society for the Promotion of Science (JSPS) Postdoctoral Fellowships for Overseas Researchers, Grant-in-Aid for Research Activity start-up and for Young Scientists (JSPS KAKENHI grant 18H06192 and 20K17242), AMED Prime (JP20gm6210013), MSD Life Science Foundation, Kidney Foundation, Salt Science Research Foundation, Smoking Research Foundation, Yukiko Ishibashi Foundation, Mochida
Memorial Foundation, Takeda Science Foundation, Astellas Foundation for Research on Metabolic Disorders, Suzuken Memorial Foundation, and Kyowa Kirin.

\section{Declarations}

Conflict of interest The author has declared that no conflict of interest exists.

Human and animal rights All procedures performed in studies involving animals were in accordance with the ethical standards of the institution or practice at which the studies were conducted (IRB approval number 2006101636-4). This article does not contain any studies with human participants performed by the author.

Open Access This article is licensed under a Creative Commons Attribution 4.0 International License, which permits use, sharing, adaptation, distribution and reproduction in any medium or format, as long as you give appropriate credit to the original author(s) and the source, provide a link to the Creative Commons licence, and indicate if changes were made. The images or other third party material in this article are included in the article's Creative Commons licence, unless indicated otherwise in a credit line to the material. If material is not included in the article's Creative Commons licence and your intended use is not permitted by statutory regulation or exceeds the permitted use, you will need to obtain permission directly from the copyright holder. To view a copy of this licence, visit http://creativecommons.org/licenses/by/4.0/.

\section{References}

1. Pavlov VA, Tracey KJ. Neural regulation of immunity: molecular mechanisms and clinical translation. Nat Neurosci. 2017;20(2):156-66. https://doi.org/10.1038/nn.4477.

2. Hasegawa $S$, Inoue T, Inagi R. Neuroimmune interactions and kidney disease. Kidney Res Clin Pract. 2019;38(3):282-94. https:// doi.org/10.23876/j.krcp.19.014.

3. Nakamura Y, Inoue T. Neuroimmune Communication in the Kidney. JMA J. 2020;3(3):164-74. https://doi.org/10.31662/jmaj. 2020-0024.

4. Bellavance MA, Rivest S. The HPA-immune axis and the immunomodulatory actions of glucocorticoids in the brain. Front Immunol. 2014;5:136. https://doi.org/10.3389/fimmu.2014.00136.

5. Breder CD, Dinarello CA, Saper CB. Interleukin-1 immunoreactive innervation of the human hypothalamus. Science. 1988;240(4850):321-4. https://doi.org/10.1126/science.3258444.

6. Breder CD, Hazuka C, Ghayur T, Klug C, Huginin M, Yasuda K, et al. Regional induction of tumor necrosis factor alpha expression in the mouse brain after systemic lipopolysaccharide administration. Proc Natl Acad Sci U S A. 1994;91(24):11393-7. https://doi. org/10.1073/pnas.91.24.11393.

7. Tracey KJ. The inflammatory reflex. Nature. 2002;420(6917):8539. https://doi.org/10.1038/nature01321.

8. Borovikova LV, Ivanova S, Zhang M, Yang H, Botchkina GI, Watkins LR, et al. Vagus nerve stimulation attenuates the systemic inflammatory response to endotoxin. Nature. 2000;405(6785):458-62. https://doi.org/10.1038/35013070.

9. Wang H, Yu M, Ochani M, Amella CA, Tanovic M, Susarla S, et al. Nicotinic acetylcholine receptor alpha7 subunit is an essential regulator of inflammation. Nature. 2003;421(6921):384-8. https://doi.org/10.1038/nature01339nature01339[pii].

10. Huston JM, Ochani M, Rosas-Ballina M, Liao H, Ochani K, Pavlov VA, et al. Splenectomy inactivates the cholinergic 
antiinflammatory pathway during lethal endotoxemia and polymicrobial sepsis. J Exp Med. 2006;203(7):1623-8. https://doi. org/10.1084/jem.20052362.

11. Rosas-Ballina M, Olofsson PS, Ochani M, Valdes-Ferrer SI, Levine YA, Reardon C, et al. Acetylcholine-synthesizing T cells relay neural signals in a vagus nerve circuit. Science. 2011;334(6052):98-101. https://doi.org/10.1126/science.12099 85.

12. Singbartl K, Formeck CL, Kellum JA. Kidney-immune system crosstalk in AKI. Semin Nephrol. 2019;39(1):96-106. https://doi. org/10.1016/j.semnephrol.2018.10.007.

13. Inoue T, Abe C, Sung SS, Moscalu S, Jankowski J, Huang L, et al. Vagus nerve stimulation mediates protection from kidney ischemia-reperfusion injury through alpha $7 \mathrm{nAChR}+$ splenocytes. J Clin Invest. 2016;126(5):1939-52. https://doi.org/10.1172/JCI83 658.

14. Inoue $\mathrm{T}$, Abe C, Kohro T, Tanaka S, Huang L, Yao J, et al. Noncanonical cholinergic anti-inflammatory pathway-mediated activation of peritoneal macrophages induces Hes 1 and blocks ischemia/ reperfusion injury in the kidney. Kidney Int. 2019;95(3):563-76. https://doi.org/10.1016/j.kint.2018.09.020.

15. Uni R, Inoue T, Nakamura $\mathrm{Y}$, Fukaya $\mathrm{D}$, Hasegawa $\mathrm{S}, \mathrm{Wu} \mathrm{CH}$, et al. Vagus nerve stimulation even after injury ameliorates cisplatin-induced nephropathy via reducing macrophage infiltration. Sci Rep. 2020;10(1):9472. https://doi.org/10.1038/ s41598-020-66295-0.

16. Boyden ES, Zhang F, Bamberg E, Nagel G, Deisseroth K. Millisecond-timescale, genetically targeted optical control of neural activity. Nat Neurosci. 2005;8(9):1263-8. https://doi.org/10.1038/ nn1525.

17. Abe $\mathrm{C}$, Inoue $\mathrm{T}$, Inglis MA, Viar KE, Huang L, Ye H, et al. C1 neurons mediate a stress-induced anti-inflammatory reflex in mice. Nat Neurosci. 2017;20(5):700-7. https://doi.org/10.1038/ nn. 4526.

18. Gigliotti JC, Huang L, Ye H, Bajwa A, Chattrabhuti K, Lee S, et al. Ultrasound prevents renal ischemia-reperfusion injury by stimulating the splenic cholinergic anti-inflammatory pathway. J Am Soc Nephrol. 2013;24(9):1451-60. https://doi.org/10.1681/ ASN.2013010084.

19. Gigliotti JC, Huang L, Bajwa A, Ye H, Mace EH, Hossack $\mathrm{JA}$, et al. Ultrasound modulates the splenic neuroimmune axis in attenuating AKI. J Am Soc Nephrol. 2015;26(10):2470-81. https://doi.org/10.1681/ASN.2014080769ASN.2014080769[pii].

20. Aibara Y, Nakashima A, Kawano KI, Yusoff FM, Mizuki F, Kishimoto $\mathrm{S}$, et al. Daily low-intensity pulsed ultrasound ameliorates renal fibrosis and inflammation in experimental hypertensive and diabetic nephropathy. Hypertension. 2020;76(6):1906-14. https:// doi.org/10.1161/HYPERTENSIONAHA.120.15237.

21. Tsui PH, Wang SH, Huang CC. In vitro effects of ultrasound with different energies on the conduction properties of neural tissue. Ultrasonics. 2005;43(7):560-5. https://doi.org/10.1016/j.ultras. 2004.12.003.

22. Colucci V, Strichartz G, Jolesz F, Vykhodtseva N, Hynynen K. Focused ultrasound effects on nerve action potential in vitro. Ultrasound Med Biol. 2009;35(10):1737-47. https://doi.org/10. 1016/j.ultrasmedbio.2009.05.002.

23. Wright CJ, Haqshenas SR, Rothwell J, Saffari N. Unmyelinated peripheral nerves can be stimulated in vitro using pulsed ultrasound. Ultrasound Med Biol. 2017;43(10):2269-83. https://doi. org/10.1016/j.ultrasmedbio.2017.05.008.

24. Kubanek J, Shi J, Marsh J, Chen D, Deng C, Cui J. Ultrasound modulates ion channel currents. Sci Rep. 2016;6:24170. https:// doi.org/10.1038/srep24170.

25. Downs ME, Lee SA, Yang G, Kim S, Wang Q, Konofagou EE. Non-invasive peripheral nerve stimulation via focused ultrasound in vivo. Phys Med Biol. 2018;63(3):035011. https://doi.org/10. 1088/1361-6560/aa9fc2.

26. DiBona GF, Kopp UC. Neural control of renal function. Physiol Rev. 1997;77(1):75-197. https://doi.org/10.1152/physrev.1997. 77.1 .75 .

27. La Grange RG, Sloop CH, Schmid HE. Selective stimulation of renal nerves in the anesthetized dog: effect on renin release during controlled changes in renal hemodynamics. Circ Res. 1973;33(6):704-12. https://doi.org/10.1161/01.res.33.6.704.

28. Barajas L, Muller J. The innervation of the juxtaglomerular apparatus and surrounding tubules: a quantitative analysis by serial section electron microscopy. J Ultrastruct Res. 1973;43(1):10732. https://doi.org/10.1016/s0022-5320(73)90073-7.

29. Drukker J, Groen GJ, Boekelaar AB, Baljet B. The extrinsic innervation of the rat kidney. Clin Exp Hypertens A. 1987;9(Suppl 1):15-31. https://doi.org/10.3109/10641968709160161.

30. Barajas L, Liu L, Powers K. Anatomy of the renal innervation: intrarenal aspects and ganglia of origin. Can J Physiol Pharmacol. 1992;70(5):735-49. https://doi.org/10.1139/y92-098.

31. Mompeo B, Maranillo E, Garcia-Touchard A, Larkin T, Sanudo $\mathrm{J}$. The gross anatomy of the renal sympathetic nerves revisited. Clin Anat. 2016;29(5):660-4. https://doi.org/10.1002/ca.22720.

32. Barajas L, Powers K. Innervation of the renal proximal convoluted tubule of the rat. Am J Anat. 1989;186(4):378-88. https:// doi.org/10.1002/aja.1001860407.

33. Kowalski R, Kreft E, Kasztan M, Jankowski M, SzczepanskaKonkel M. Chronic renal denervation increases renal tubular response to $\mathrm{P} 2 \mathrm{X}$ receptor agonists in rats: implication for renal sympathetic nerve ablation. Nephrol Dial Transplant. 2012;27(9):3443-8. https://doi.org/10.1093/ndt/gfs087.

34. Marfurt CF, Echtenkamp SF. Sensory innervation of the rat kidney and ureter as revealed by the anterograde transport of wheat germ agglutinin-horseradish peroxidase (WGA-HRP) from dorsal root ganglia. J Comp Neurol. 1991;311(3):389-404. https:// doi.org/10.1002/cne.903110309.

35. Kopp UC. Role of renal sensory nerves in physiological and pathophysiological conditions. Am J Physiol Regul Integr Comp Physiol. 2015;308(2):R79-95. https://doi.org/10.1152/ajpregu. 00351.2014.

36. Okusa MD, Rosin DL, Tracey KJ. Targeting neural reflex circuits in immunity to treat kidney disease. Nat Rev Nephrol. 2017;13(11):669-80. https://doi.org/10.1038/nrneph.2017.132.

37. Amsterdam WA, van PJ Blankestijn R Goldschmeding RL Bleys, . The morphological substrate for Renal Denervation: nerve distribution patterns and parasympathetic nerves. postmortem histological study. Ann Anat. 2016;204(71):79. https:// doi.org/10.1016/j.aanat.2015.11.004.

38. Maeda S, Jun JG, Kuwahara-Otani S, Tanaka K, Hayakawa T, Seki M. Non-neuronal expression of choline acetyltransferase in the rat kidney. Life Sci. 2011;89(11-12):408-14. https://doi. org/10.1016/j.lfs.2011.07.011.

39. Park J, Shrestha R, Qiu C, Kondo A, Huang S, Werth M, et al. Single-cell transcriptomics of the mouse kidney reveals potential cellular targets of kidney disease. Science. 2018;360(6390):758-63. https://doi.org/10.1126/science.aar21 31.

40. Der E, Suryawanshi H, Morozov P, Kustagi M, Goilav B, Ranabothu S, et al. Tubular cell and keratinocyte single-cell transcriptomics applied to lupus nephritis reveal type I IFN and fibrosis relevant pathways. Nat Immunol. 2019;20(7):915-27. https:// doi.org/10.1038/s41590-019-0386-1.

41. Fu J, Akat KM, Sun Z, Zhang W, Schlondorff D, Liu Z, et al. Single-Cell RNA profiling of glomerular cells shows dynamic changes in experimental diabetic kidney disease. J Am Soc Nephrol. 2019;30(4):533-45. https://doi.org/10.1681/ASN.20180 90896. 
42. Wilson PC, Wu H, Kirita Y, Uchimura K, Ledru N, Rennke HG, et al. The single-cell transcriptomic landscape of early human diabetic nephropathy. Proc Natl Acad Sci USA. 2019;116(39):1961925. https://doi.org/10.1073/pnas.1908706116.

43. Kirita Y, Wu H, Uchimura K, Wilson PC, Humphreys BD. Cell profiling of mouse acute kidney injury reveals conserved cellular responses to injury. Proc Natl Acad Sci USA. 2020;117(27):15874-83. https://doi.org/10.1073/pnas.20054 77117.

44. Kuppe C, Ibrahim MM, Kranz J, Zhang X, Ziegler S, Perales-Paton $\mathrm{J}$, et al. Decoding myofibroblast origins in human kidney fibrosis. Nature. 2020. https://doi.org/10.1038/s41586-020-2941-1.

45. Hasegawa S, Inoue T, Nakamura Y, Fukaya D, Uni R, Wu CH, Fujii R, Peerapanyasut W, Taguchi A, Kohro T, Yamada S, Katagiri M, Ko T, Nomura S, Ozeki NA, Susaki EA, Ueda HR, Akimitsu N, Wada Y, Komuro I, Nangaku M, and Inagi R. Activation of sympathetic signaling in macrophages blocks systemic inflammation and protects against renal ischemia/reperfusion injury. J Am Soc Nephrol. 2021 in press.

46. Jing M, Zhang P, Wang G, Feng J, Mesik L, Zeng J, et al. A genetically encoded fluorescent acetylcholine indicator for in vitro and in vivo studies. Nat Biotechnol. 2018;36(8):726-37. https:// doi.org/10.1038/nbt.4184.

47. Feng J, Zhang C, Lischinsky JE, Jing M, Zhou J, Wang H, et al. A genetically encoded fluorescent sensor for rapid and specific in vivo detection of norepinephrine. Neuron. 2019;102(4):745-61. e8. https://doi.org/10.1016/j.neuron.2019.02.037.

Publisher's Note Springer Nature remains neutral with regard to jurisdictional claims in published maps and institutional affiliations. 